\title{
Perbedaan Kualitas Tidur Lansia yang Tinggal Bersama Keluarga dengan Lansia di PSTW
}

\author{
Muhammad Ischaq Nabili ${ }^{1}$, Wahyu Dewi Sulistyarini ${ }^{2}$ \\ 1, 2Sekolah Tinggi Ilmu Kesehatan Alma Ata Yogyakarta \\ Jalan Ringroad Barat Daya No 1 Tamantirto, Kasihan, Bantul Yogyakarta
}

\begin{abstract}
Abstrak
Proses penuaan menyebabkan lansia mengalami perubahan fisik dan fungsi, mental dan psikososial. Kebutuhan tidur pun berubah seiring bertambahnya usia. Kualitas tidur di pengaruhi oleh beberapa faktor di antaranya adalah lingkungan atau tempat tinggal. Tujuan penelitian ini untuk mengetahui perbedaan kualitas tidur lansia yang tinggal bersama keluarga di Dukuh Kajen Bantul dengan lansia di PSTW Unit Budi Luhur Yogyakarta. Jenis penelitian ini adalah penelitian kuantitatif non eksperimental dengan rancangan penelitian cross sectional. Variabel independen yakni tempat tinggal, variabel dependen yakni kualitas tidur lansia. Hasil analisis dengan menggunakan uji statistik Chi-Square didapatkan bahwa lansia yang tinggal bersama keluarga di Dukuh Kajen sebagian besar memiliki kualitas tidur kurang sebanyak 55 orang (49,6\%). Lansia yang tinggal di PSTW Yogyakarta Unit Budi Luhur sebagian besar memiliki kualitas tidur kurang sebanyak 41 orang $(66,1 \%)$. Lansia yang mempunyai kualitas tidur cukup atau baik lebih banyak pada lansia yang tinggal bersama keluarga di Dukuh Kajen (44,1\%) dibandingkan dengan lansia yang tinggal di PSTW Yogyakarta Unit Budi Luhur (24,2\%). Nilai Chi-square didapatkan nilai $X^{2}$ sebesar 6.852 dengan p-value sebesar 0.033. Simpulan penelitian ada perbedaan kualitas tidur lansia yang tinggal bersama keluarga di Dukuh Kajen Bantul dengan lansia di PSTW Unit Budi Luhur Yogyakarta
\end{abstract}

Kata Kunci : Lansia, Tempat Tinggal, Kualitas Tidur

\section{Differences of Sleeping Quality Between Elderly Living with Family and Living in the PSTW}

\begin{abstract}
Ageing process has led to physical and functional changing, as well as mental and psychosocial. The sleeping need has also changing as long as ageing. Sleeping quality is influenced by several factors including circumstances and living place. The purpose of this research is to compare sleeping quality elderly living with family at Dukuh Kajen Bantul with those living at PSTW Budi Luhur Yogyakarta. This quantitative non experimental study used cross-sectional design. Independent variable in this research was livin place, while dependent variable was sleeping quality on elderly. Data was tested using chi-square and the result was those who lives with family mostly having less sleeping quality at 55 people (49,6\%), whereas, quality of sleeping older people lives in PSTW was 41 people (66,1\%). Elders who have categorized as less sleeping quality mostly living with family (44,1\%) compared with $24,2 \%$ who live in PSTW Budi Luhur Yogyakarta. The value Chi-Square was $X^{2}=6.852$ with $p$ value $=0.033$. Conclusion, there was significant differences on quality of sleeping elderly living with family and living in PSTW Budi Luhur.
\end{abstract}

Keywords: elderly, sleep quality

Info Artikel:

Artikel dikirim pada 18 November 2013

Artikel diterima pada 18 November 2013 


\section{Pendahuluan}

Penuaan adalah suatu proses alami yang tidak dapat dihindarkan dan berjalan secara terusmenerus dan berkesinambungan. Selanjutnya akan menyebabkan perubahan anatomis, fisiologis, dan biokimia pada tubuh sehingga akan mempengaruhi fungsi dan kemampuan tubuh secara keseluruhan. ${ }^{1}$

Semakin bertambahnya usia berpengaruh terhadap penurunan dari periode tidur. Kebutuhan tidur akan berkurang dari usia bayi sampai usia lanjut. Orang yang berusia lebih dari 60 tahun sering menyampaikan keluhan gangguan tidur, terutama masalah kurang tidur. ${ }^{2}$

Sebagian besar lansia berisiko mengalami gangguan tidur yang disebabkan oleh banyak faktor. Gangguan tidur menyerang $50 \%$ orang yang berusia 65 tahun atau lebih yang tinggal di rumah dan $66 \%$ orang yang tinggal di fasilitas perawatan jangka panjang. Gangguan tidur mempengaruhi kualitas hidup dan berhubungan dengan angka mortalitas yang lebih tinggi. ${ }^{3}$

Tempat tinggal dan lingkungan merupakan hal yang penting karena mempunyai dampak utama pada kesehatan lansia. Keluarga harus terlibat aktif dalam mempertahankan dan meningkatkan status kesehatan lansia. ${ }^{5}$ Namun, Beberapa keluarga mempertimbangkan untuk menggunakan perawatan jompo saat perawatan di rumah dirasakan semakin sulit. ${ }^{4}$ Para lansia yang dititipkan di panti pada dasarnya memiliki sisi negative dan positif. Diamati dari sisi positif, lingkungan panti dapat memberikan kesenangan bagi lansia. Sosialisasi di lingkungan yang memiliki tingkat usia sebaya akan menjadi hiburan tersendiri sehingga kebersamaan ini dapat mengubur kesepian yang biasanya mereka alami. Akan tetapi jauh di lubuk hati mereka merasa jauh lebih nyaman berada di dekat keluarganya. ${ }^{1}$

Berdasarkan hasil survey yang dilakukan di Dukuh Kajen Desa Bangunjiwo Kecamatan Kasihan Bantul terdapat 152 orang lansia. Peniliti juga melakukannya di Panti Sosial Tresna Werdha (PSTW) Yogyakarta Unit Budi Luhur yang masih berada di wilayah Dukuh Kajen dan diketahui jumlah lansia di tempat ini adalah 88 orang. Selanjutnya peneliti melakukan wawancara study pendahuluan di PSTW Yogyakarta Unit Budi Luhur menggunakan kuesioner kepada 3 orang lansia yang tinggal di PSTW dan 3 orang lansia yang tinggal bersama keluarga di rumah yang mengikuti program Day Care. Di dapatkan hasil bahwa dari 3 orang responden lansia yang tinggal di PSTW ketiganya memiliki kualitas tidur kurang, sedangkan responden lansia program Day Care, 2 orang memiliki kualitas tidur baik dan 1 orang cukup.
Dari uraian di atas, peneliti tertarik untuk melakukan penelitian tentang perbedaan kualitas tidur lansia yang tinggal bersama keluarga di Dukuh Kajen dengan lansia di PSTW Unit Budi Luhur Yogyakarta.

\section{Bahan dan Metode}

Jenis penelitian ini adalah penelitian kuantitatif non eksperimental dengan rancangan penelitian cross sectional. Penelitian ini merupakan penelitian dengan pendekatan analisis deskriptif komparatif. Lokasi penelitian dilakukan di Dukuh Kajen Desa Bangunjiwo Kecamatan Kasihan Kabupaten Bantul dan di PSTW Yogyakarta Unit Budi Luhur. Penelitian ini dilaksanakan pada bulan Februari 2013 hingga Maret 2013. Subyek penelitian ini adalah seluruh lansia di Dukuh Kajen dan lansia di PSTW Yogyakarta Unit Budi Luhur yang telah sesuai dengan kriteria inklusi dan ekslusi.

Teknik pengambilan sampel yang digunakan adalah teknik total sampling. Peneliti mengambil sampel dari seluruh lansia yang tinggal di Dukuh Kajen Desa Bangunjiwo Kecamatan Kasihan Kabupaten Bantul sebanyak 111 orang dan Lansia yang tinggal di PSTW Yogyakarta Unit Budi Luhur sebanyak 62 orang. Variabel penelitian ini terdiri dari variabel independen yaitu keluarga dan PSTW dan Variabel dependen yaitu kualitas tidur. Jenis data yang diambil adalah data primer yang diperoleh dari responden melalui wawancara menggunakan kuesioner. Kuesioner yang digunakan adalah PSQI (The Pittsburgh Sleep Quality Index) untuk mengukur kualitas tidur dalam interval satu bulan. Dari metode ini akan didapatkan output berupa sleeping index yang merupakan suatu skor dengan pembobotan tertentu. Index tersebut nantinya akan menggambarkan seberapa baikkah kualitas tidur seseorang. Data penelitian tersebut kemudian dianalisis menggunakan uji chi-square $\left(x^{2}\right)$.

\section{Hasil dan Pembahasan}

Responden dalam penelitian ini adalah lansia di Dukuh Kajen yang berjumlah 145 orang dan di PSTW Yogyakarta Unit Budi Luhur berjumlah 88 orang. Keseluruhan responden disesuaikan dengan kiteria inklusi dan eksklusi yang telah ditentukan. Kriteria eksklusi dalam penelitian ini adalah lansia dengan gangguan kognitif berat yang di ukur menggunakan Short Portable Mental Status Questionairre (SPMSQ) dan lansia yang tinggal di ruang isolasi untuk lansia di PSTW Yogyakarta Unit Budi Luhur. Di Dukuh Kajen terdapat 34 orang lansia yang mengalami gangguan kognitif berat dan di PSTW Yogyakarta Unit Budi Luhur sebanyak 14 orang lansia yang mengalami 
gangguan kognitif berat serta 12 orang lansia tinggal di ruang isolasi. Jadi didapatkan sampel penelitian di Dukuh Kajen sebanyak 111 orang dan di PSTW Yogyakarta Unit Budi Luhur sebanyak 62 orang.

\section{Karakteristik Responden}

Karakteristik responden dalam penelitian ini meliputi umur, jenis kelamin dan tingkat pendidikan yang diuraikan sebagai berikut :

Tabel 1. Karakteristik responden

\begin{tabular}{lcccc}
\hline \multirow{2}{*}{ Karakteristik } & \multicolumn{4}{c}{ Tempat Tinggal } \\
\cline { 2 - 5 } & \multicolumn{2}{c}{ Dukuh Kajen } & \multicolumn{2}{c}{ PSTW } \\
\cline { 2 - 5 } & $\mathrm{f}$ & $\%$ & $\mathrm{f}$ & $\%$ \\
\hline Umur & 84 & 75.7 & 35 & 56.5 \\
\hline $60-74$ & 27 & 24.3 & 25 & 40.3 \\
$75-90$ & 0 & 0 & 2 & 3.2 \\
\hline 90 & 111 & 100.0 & 62 & 100.0 \\
\hline \multicolumn{1}{c}{ Total } & & & & \\
\hline Jenis Kelamin & 62 & 55.9 & 26 & 41.9 \\
Laki-laki & 49 & 44.1 & 36 & 58.1 \\
perempuan & 111 & 100.0 & 62 & 100,0 \\
\hline Total & & & & \\
\hline Tingkat Pendidikan & 55 & 49.5 & 29 & 46.8 \\
Tidak sekolah & 33 & 29.7 & 10 & 16.1 \\
SD & 7 & 6.3 & 9 & 14.5 \\
SMP & 14 & 12.6 & 11 & 17.7 \\
SMA & 2 & 1.8 & 3 & 4.8 \\
PT & 111 & 100,0 & 62 & 100,0 \\
\hline \multicolumn{2}{c}{ Total } & & &
\end{tabular}

Sumber : Data Primer 2013

Tabel 1. menunjukkan bahwa berdasarkan umur sebagian besar lansia berumur 60-74 tahun, di Dukuh Kajen sebanyak 84 orang $(75,7 \%)$ dan di PSTW Yogyakarta Unit Budi Luhur sebanyak 35 orang (56,5\%).

Berdasarkan jenis kelamin menunjukkan bahwa jumlah lansia laki-laki di Dukuh Kajen sebanyak 62 orang $(55,9 \%)$ lebih banyak dari lansia perempuan sebanyak 49 orang $(44,1 \%)$, Sedangkan di PSTW Yogyakarta Unit Budi Luhur lansia perempuan sebanyak 26 orang $(58,1 \%)$ lebih banyak dari lansia laki-laki sebanyak 26 orang $(41,9 \%)$. Ini menunjukkan bahwa lansia di Dukuh Kajen sebagian besar adalah laki-laki. Sedangkan di PSTW Yogyakarta Unit Budi sebagian besar merupakan lansia perempuan.

Berdasarkan tingkat pendidikan menunjukkan bahwa sebagian besar lansia mempunyai riwayat pendidikan tidak sekolah, di Dukuh Kajen sebanyak 55 orang $(49,5 \%)$ dan di PSTW Yogyakarta Unit Budi Luhur sebanyak 29 orang $(46,8 \%)$.

Tabel 2. Distribusi Kualitas Tidur Lansia

\begin{tabular}{|c|c|c|c|c|}
\hline \multirow{3}{*}{ Kriteria } & \multicolumn{3}{|c|}{ Tempat Tinggal } & \\
\hline & \multicolumn{2}{|c|}{ Dukuh Kajen } & \multirow{2}{*}{$\frac{\text { PSTW }}{\mathrm{F}}$} & \\
\hline & $f$ & $\%$ & & $\%$ \\
\hline Kurang & 55 & 49.6 & 41 & 66.1 \\
\hline Cukup & 49 & 44.1 & 15 & 24.2 \\
\hline Baik & 7 & 6.3 & 6 & 9.7 \\
\hline Total & 111 & 100,0 & 62 & 100,0 \\
\hline
\end{tabular}

Sumber: Data Primer 2013

Tabel 2. menunjukkan distribusi kualitas tidur lansia, berdasarkan tabel tersebut dapat dilihat bahwa sebagian besar lansia yang memiliki kualitas tidur kurang, di Dukuh Kajen sebanyak 55 orang (49.6\%) dan di PSTW Yogyakarta Unit Budi Luhur sebanyak 41 orang $(66.1 \%)$.

Tabel 3. menunjukkan bahwa hasil uji statistik dengan menggunakan uji chi-square didapatkan hasil nilai $X^{2}$ sebesar 6.852 dengan tingkat signifikansi ( $p$-value) sebesar 0.033 . Dengan demikian $p<0,05$ sehingga Ho ditolak yang berarti ada perbedaan kualitas tidur lansia yang tinggal di Dukuh Kajen dan lansia di PSTW Yogyakarta Unit Budi Luhur, yaitu proporsi lansia yang mempunyai kualitas tidur kurang lebih banyak pada lansia di PSTW Yogyakarta Unit Budi Luhur dibandingkan pada lansia yang tinggal bersama keluarga di Dukuh Kajen. Sebaliknya lansia yang mempunyai kualitas tidur cukup atau baik lebih banyak pada lansia yang tinggal bersama keluarga di Dukuh Kajen dibandingkan dengan lansia yang tinggal di PSTW Yogyakarta Unit Budi Luhur.

\section{Distribusi Frekuensi Berdasar Umur Lansia}

Karakteristik responden berdasar umur menurut hasil penelitian pada table 1. menunjukkan bahwa

Tabel 3. Perbedaan Kualitas Tidur Lansia yang Tinggal di Dukuh Kajen dan di PSTW Yogyakarta Unit Budi Luhur

\begin{tabular}{|c|c|c|c|c|c|c|c|c|c|c|}
\hline \multirow{3}{*}{$\begin{array}{l}\text { Tempat } \\
\text { Tinggal }\end{array}$} & \multicolumn{6}{|c|}{ Kualitas Tidur } & \multirow{2}{*}{\multicolumn{2}{|c|}{ Total }} & $X^{2}$ & $p$-Value \\
\hline & \multicolumn{2}{|c|}{ Kurang } & \multicolumn{2}{|c|}{ Cukup } & \multicolumn{2}{|c|}{ Baik } & & & & \\
\hline & $f$ & $\%$ & $f$ & $\%$ & $f$ & $\%$ & $f$ & $\%$ & & \\
\hline Dukuh Kajen & 55 & 49.6 & 49 & 44.1 & 7 & 6.3 & 111 & 100 & 6.852 & 0.033 \\
\hline PSTW & 41 & 66.1 & 15 & 24.2 & 6 & 9.7 & 62 & 100 & & \\
\hline Total & 96 & 55.5 & 64 & 37 & 13 & 7.5 & 173 & 100 & & \\
\hline
\end{tabular}

Sumber : Data Primer 2013 
sebagian besar lansia berusia antara 60-74 tahun, di Dukuh Kajen sebanyak 84 orang $(75,7 \%)$ dan di PSTW Yogyakarta Unit Budi Luhur sebanyak 35 orang $(56,5 \%)$. Peneliti mendapatkan keterangan dari lansia, pada umumnya mereka menyadari bahwa kualitas tidur mereka berkurang seiring dengan bertambahnya umur.

Sejak meninggalkan masa remaja, kebutuhan tidur seseorang menjadi relatif tetap. Faktor umur merupakan faktor terpenting yang berpengaruh terhadap kualitas tidur. Keluhan kualitas tidur seiring dengan bertambahnya umur. ${ }^{6}$

Pada kelompok lanjut usia 40 tahun dijumpai $7 \%$ kasus yang mengeluh mengenai masalah tidur (hanya dapat tidur tidak lebih dari 5 jam sehari). Hal yang sama dijumpai pada $22 \%$ pada kelompok usia 75 tahun. Demikian pula kelompok lansia lebih banyak mengeluh terbangun lebih awal. Selain itu, terdapat $30 \%$ kelompok usia 70 tahun yang banyak terbangun di waktu malam hari. Angka ini ternyata tujuh kali lebih besar dibandingkan dengan kelompok usia 20 tahun. ${ }^{7}$

\section{Distribusi Frekuensi Berdasar Jenis Kelamin Lansia}

Karakteristik responden berdasarkan jenis kelamin pada table 1. menunjukkan bahwa lansia di Dukuh Kajen sebagian besar adalah laki-laki. Sedangkan di PSTW Yogyakarta Unit Budi sebagian besar merupakan lansia perempuan.

Berdasarkan data statistik penduduk lansia provinsi Daerah Istimewa Yogyakarta dari hasil sensus penduduk tahun 2010, jumlah lansia perempuan sebanyak 249.784 orang lebih banyak dari jumlah lansia laki-laki sebanyak 198.439 orang. ${ }^{8}$ Dalam penelitian ini peneliti menemukan jumlah lansia perempuan di Dukuh Kajen lebih sedikit dari lansia laki-laki. Hal ini dapat di karenakan cakupan wilayah yang masih kecil sehingga sebaran lansia di Dukuh Kajen berdasarkan jenis kelamin belum dapat mewakili jumlah prosentase secara keseluruhan dari jumlah lansia di Provinsi DIY.

Pada penelitian yang dilakukan oleh Shintya (2012) tentang pengaruh kualitas tidur pada kualitas hidup lansia penderita penyakit kronis pada aspek spiritual berdasarkan jenis kelamin, hasil yang diperoleh menyatakan bahwa tidak ada pengaruh jenis kelamin dalam pengaruh kualitas tidur pada kualitas hidup lansia penderita penyakit kronis. ${ }^{9}$

\section{Distribusi Frekuensi Berdasar Tingkat Pendidikan Lansia}

Hasil penelitian pada tabel 1. menunjukkan bahwa sebagian besar lansia mempunyai riwayat pendidikan tidak sekolah, di Dukuh Kajen sebanyak 55 orang $(49,5 \%)$ dan di PSTW Yogyakarta Unit Budi Luhur sebanyak 29 orang (46,8\%). Lansia di Dukuh Kajen dan di PSTW Yogyakarta Unit Budi Luhur sebagian besar berasal dari masyarakat dengan tingkat ekonomi rendah sehingga pada masa sekolah dahulu mereka tidak memiliki biaya untuk sekolah. Tingkat pendidikan ini mempunyai hubungan dengan tingkat pengetahuan, serta tingkat penghasilan seseorang. Orang yang mempunyai pendidikan dan pengetahuan cenderung akan meningkat penghasilannya sehingga jika mereka sakit akan memilih sarana kesehatan yang lebih baik. Oleh karenanya semua ini akan berdampak terhadap adanya usia harapan hidup yang semakin meningkat. ${ }^{10}$

\section{Kualitas Tidur Lansia}

Hasil penelitian pada tabel 2. menunjukkan bahwa sebagian besar lansia memiliki kualitas tidur kurang, di Dukuh Kajen sebanyak 55 orang (49.6\%) dan di PSTW Yogyakarta Unit Budi Luhur sebanyak 41 orang $(66.1 \%)$.

Siklus tidur pada setiap individu berbeda dan relatif dipengaruhi oleh penuaan. Pada lansia tidur sering kali terlihat gelisah dan waktu terjaganya menjadi lebih lama. Sedangkan pada orang muda, sekitar $15 \%$ waktu tidurnya dihabiskan pada fase keempat. Fase keempat biasanya tidak ditemukan pada orang tua. Demikian juga dengan fase REM yang mengalami penurunan, yaitu $28 \%$ dari pasca pubertas menjadi $18 \%$ pada orang tua. Hal ini menunjukkan bahwa tidur menjadi lebih singkat sehingga menyebabkan berkurangnya kesegaran sesuai bertambahnya usia. Pada lansia memiliki pola tidur yang berbeda dengan remaja. Kebutuhan tidur lansia semakin menurun karena dorongan homeostasis untuk tidur pun berkurang. ${ }^{11}$

Tingginya masalah tidur yang terjadi pada lansia memerlukan penanganan yang sesuai untuk meningkatkan pemenuhan kebutuhan tidur. Pemenuhan kebutuhan tidur setiap orang berbedabeda dan terlihat dari kualitas tidurnya. Kebutuhan kualitas tidur ada yang terpenuhi dengan baik dan ada yang mengalami gangguan. ${ }^{2}$

\section{Perbedaan Kualitas Tidur Lansia yang Tinggal Bersama Keluarga di Dukuh Kajen Bantul dan Lansia di PSTW Yogyakarta Unit Budi Luhur}

Hasil penelitian ini menunjukkan bahwa lansia di Dukuh Kajen maupun di PSTW Yogyakarta Unit Budi Luhur sebagian besar memiliki kualitas tidur kurang. Namun perbandingan prosentase antara 
lansia yang memiliki kualitas tidur cukup di Dukuh Kajen dan di PSTW Yogyakarta Unit Budi Luhur cukup signifikan, yaitu sebanyak $44,1 \%$ di Dukuh Kajen dan sebanyak $24,2 \%$ di PSTW Yogyakarta Unit Budi Luhur dengan selisih prosentase mencapai 19,9\%. Hal ini menunjukkan bahwa kualitas tidur lansia yang tinggal bersama keluarga di Dukuh Kajen lebih baik dari lansia di PSTW Yogyakarta Unit Budi Luhur.

Berdasarkan wawancara peneliti menemukan bahwa perbedaan tersebut sangat dipengaruhi oleh faktor lingkungan tempat tinggal lansia. Lansia yang tinggal bersama keluarga di Dukuh Kajen cenderung merasa lebih nyaman tinggal di rumah sendiri bersama keluarga sehingga kondisi tersebut mendukung terjaganya kualitas tidur mereka meskipun terdapat pula sebagian kecil lansia memiliki kualitas tidur kurang yang disebabkan oleh beberapa faktor seperti adanya masalah dengan keluarga, kondisi penyakit yang sedang di alami, serta masalah ekonomi yang menjadi stressor penyebab gangguan tidur. Lansia yang tinggal di PSTW Yogyakarta Unit Budi Luhur sebagian besar merasa kurang nyaman dengan tempat tinggal mereka sehingga berpengaruh terhadap pola tidur dan kualitas tidurnya. Gangguan tidur yang mereka alami sebagian besar berasal dari kondisi tempat tinggal yang kurang nyaman, adanya gangguan atau masalah dari sesama penghuni panti lainnya, kondisi penyakit yang sedang dialami, serta sebagian kecil mengalami kecemasan terhadap keluarga.

Tempat tinggal dan lingkungan merupakan hal yang penting karena mempunyai dampak utama pada kesehatan lansia ${ }^{4}$ Lingkungan dapat meningkatkan atau menghalangi seseorang untuk tidur. Pada lingkungan yang tenang akan memungkinkan seseorang dapat tidur dengan nyenyak. Sebaliknya lingkungan yang ribut, bising dan gaduh akan menghambat sesorang untuk tidur ${ }^{12}$

Lansia yang tinggal bersama keluarga di Dukuh Kajen cenderung merasa lebih nyaman tinggal di rumah sendiri bersama keluarga, hal ini sesuai dengan pendapat Maryam et al 2008. Bahwa setiap anggota keluarga memiliki peranan penting dalam melakukan perawatan terhadap lansia. Dalam mempertahankan kesehatan lansia, keluarga merupakan support sistem utama. Peranan keluarga dalam perawatan lansia antara lain menjaga atau merawat lansia, mempertahankan dan meningkatkan status mental, mengantisipasi perubahan sosial ekonomi, serta memberikan motivasi dan memfasilitasi kebutuhan spiritual bagi lansia. Kondisi ini yang nantinya dapat mempengaruhi lansia yang tinggal bersama keluarga untuk mepertahankan kualitas tidurnya. ${ }^{1}$

Lansia yang tinggal di panti PSTW Yogyakarta Unit Budi Luhur sebagian besar adalah Iansia terlantar yang memiliki masalah ekonomi dan sosial yang tidak memiliki keluarga dan tempat tinggal. Perasaan jauh dari keluarga dan rasa terbuang dari orang-orang yang disayangi itulah yang membuat lansia merasa dirinya tersisih. Lansia yang tidak dapat menyesuaikan diri dengan lingkungan dapat mempengaruhi kondisi ketahanan tubuh lansia yang diterimanya dari lingkungan sekitar, maka tekanan atau stressor pada diri lansia berpengaruh pada pola tidur dan kualitas tidurnya.

Stress dan lingkungan merupakan salah satu faktor yang mempengaruhi kualitas tidur seseorang. Penelitian yang dilakukan oleh Rosita (2012) tentang Stressor Sosial Biologi Lansia Panti Wredha Usia dan Lansia Tinggal Bersama Keluarga di Surabaya menjelaskan bahwa lansia yang di panti dengan lansia yang bersama keluarga memiliki perbedaan karakteristik maupun perilaku dalam kesehariannya. Perbedaan tersebut mengacu pada stressor dari lingkungan internal maupun eksternal yang diterima lansia. Lansia yang bersama keluarga, secara kondisi lingkungan tempat tinggal mempengaruhi timbulnya suatu stressor dan hal tersebut mempengaruhi kondisi psikologis dari para lansia, seperti perasaan marah, kecewa atau tertekan terhadap kondisi yang dialaminya seperti terjadi atau timbulnya masalah di dalam keluarga. Stressor atau tekanan dari lingkungan internal dan eksternal pada lansia di panti ialah lebih kepada hubungan antara penghuni yang tidak cocok dalam bergaul antara satu dengan lainnya, sehingga dapat menimbulkan pertengkaran dengan sesama penghuni panti. Para lansia dapat mengalami ketidakcocokan dengan yang lainnya. Selain itu, para lansia juga dapat berhubungan dengan hamonis pada sesama penghuni. ${ }^{13}$

\section{Simpulan dan Saran}

\section{Simpulan}

Kesimpulan dari penelitian ini adalah :

1. Lansia yang tinggal bersama keluarga di Dukuh Kajen sebagian besar memiliki kualitas tidur kurang sebanyak 55 orang $(49,6 \%)$.

2. Lansia yang tinggal di PSTW Yogyakarta Unit Budi Luhur sebagian besar memiliki kualitas tidur kurang sebanyak 41 orang $(66,1 \%)$.

3. Lansia yang mempunyai kualitas tidur cukup atau baik lebih banyak pada lansia yang tinggal bersama keluarga di Dukuh Kajen $(44,1 \%)$ dibandingkan dengan lansia yang tinggal di PSTW Yogyakarta Unit Budi Luhur (24,2\%).

4. Ada perbedaan kualitas tidur lansia yang tinggal bersama keluarga di Dukuh Kajen dan lansia di PSTW Yogyakarta Unit Budi Luhur. 


\section{Saran}

1. Bagi lansia

Lansia perlu mengatur aktivitas yang seimbang dan menghindari hal-hal yang dapat memicu terjadinya gangguan tidur sehingga dapat memperoleh jumlah istirahat yang cukup. Dengan demikian diharapkan kualitas tidurnya menjadi lebih baik dari sebelumnya dan gangguan tidur berkurang.

2. Bagi keperawatan

Perawat agar lebih aktif dalam memberikan penyuluhan dan asuhan keperawatan, terutama mengenai kualitas tidur.

3. Bagi Pengurus Panti

Khususnya bagi pengurus PSTW Yogyakarta Unit Budi Luhur, sebagai pengganti keluarga hendaknya meningkatkan dalam pemberian dukungan keluarga, seperti memberikan kasih sayang pada lansia, memberikan pujian, membantu kegiatan dalam sehari-harinya.

4. Bagi peneliti lain

Perlu dikaji variabel-variabel lain yang berhubungan dengan kualitas tidur, seperti faktor penyakit, latihan dan kelelahan, obat, nutrisi, motivasi, dan stress psikologi.

\section{Daftar Pustaka}

1. Maryam RS, Ekasari MF, Rosidawati, Jubaedi A, Batubara I. 2008. Mengenal Usia Lanjut dan Perawatannya. Salemba Medika, Jakarta.

2. Hidayat A.A. 2008. Pengantar Kebutuhan Dasar Manusia Aplikasi Konsep dan Proses Keperawatan. Salemba Medika, Surabaya.
3. Stanley, Mickey, dan Patricia. 2006. Buku Ajar Keperawatan Gerontik. EGC, Jakarta.

4. Potter, Patricia A. dan Perry. 2005. Buku Ajar Fundamental Keperawatan: Konsep, Proses, dan Praktik, Vol.I, E/4. EGC, Jakarta.

5. Nugroho, Wahjudi. 2006. Keperawatan Gerontik \& Geriatrik Edisi 3. EGC, Jakarta.

6. Widuri, Hesti. 2010. Asuhan Keperawatan Pada Lanjut Usia ditatanan Klinik. Fitramaya, Yogyakarta.

7. Bandiyah, Siti. 2009. Lanjut usia dan Keperawatan Gerontik. Nuha Medika, Yogyakarta.

8. BPS. 2010. Statistik Penduduk Lanjut Usia Provinsi DI Yogyakarta 2010. BPS, Jakarta.

9. Shintya, LA. 2012. Pengaruh Kualitas Tidur Pada Kualitas Hidup Lansia Penderita Penyakit Kronis Di Rumah Sakit Advent Manad. Dalam http://igenursing.weebly.com/ uploads/1/4/3/9/14390416/fix_jku_mem_lea.pdf. Jumat, 3 Mei 2013, jam 14.30 WIB.

10. Komnas Lansia, 2011. Lanjut Usia Dan Dampak Sistemik Dalam Siklus Kehidupan. Dalam http:// www.komnaslansia.go.id/modules.php?name= News\&file=article\&sid=63. Jumat, 3 Mei 2013, jam 13.30 WIB.

11. Putra SR. 2011. Tips Sehat dengan Pola Tidur Tepat dan Cerdas. Buku Biru, Yogyakarta.

12. Asmadi. 2008. Teknik Prosedural Keperawatan: Konsep dan Aplikasi Kebutuhan Dasar Klien. Salemba Medika, Jakarta.

13. Rosita. 2012. Stressor Sosial Biologi Lansia Panti Werdha Usia dan Lansia Tinggal Bersama Keluarga. Dalam http://journal.unair.ac.id/ filerPDF/04 Rosita ---- Lansia di Panti WerdhaUsia dan Lansia Tinggal Bersama Keluarga.pdf. Jumat, 3 Mei 2013, jam 15.00 WIB. 